\title{
FAKTOR INTERNAL EKSTERNAL DALAM BAURAN PEMASARAN PRODUK UKM KOPI DADONG
}

\author{
Pande Komang Suparyana \\ Program Studi Agribisnis, Fakultas Pertanian, Universitas Mataram \\ Email : pandesuparyana@unram.ac.id \\ Sharfina Nabilah \\ Program Studi Agribisnis, Fakultas Pertanian, Universitas Mataram \\ Email : sharfina@unram.ac.id
}

Ni Putu Sukanteri

Program Studi Agribisnis, Fakultas Pertanian dan Bisnis, Universitas Mahasaraswati Denpasar

Email : putusukanteri@gmail.com

\begin{abstract}
Abstrak
Lingkungan internal memberikan gambaran bahwa perusahaan memiliki kekuatan (strengths) atau kelemahan (weakness) di bidang manajemen produksi, operasi pemasaran dan distribusi, organisasi sumber daya manusia, keuangan dan akuntansi. Sedangkan lingkungan eksternal adalah analisis yang tersusun dari sekumpulan-sekumpulan kekuatan-kekuatan yang timbul dan berada di luar jangkauan serta biasanya terlepas dari situasi operasional perusahaan. Tujuan dari penelitian ini adalah Mengidentifikasi faktor internal dan eksternal bauran pemasaran pada UKM Kopi Dadong di Desa Belantih. Responden dalam penelitian ini adalah bapak Dharma dan ibu Dewa Ayu sebagai pemilik usaha kopi dadong. Penelitian ini menggunakan rancangan penelitian deskriptif. Rancangan penelitian ini di gunakan karena mampu menggambarkan analisis lingkungan internal dan eksternal dalam bauran pemasaran produk Kopi Dadong. Dari hasil penelitian diketahui faktor eksternal Bauran Pemasaran kopi Dadong adalah Adanya dukungan pemerintah dalam hal pameran produk pertanian dalam pengenalan produk kopi; Besarnya minat pemuda dengan lifestyle diperkotaan dalam mengkonsumsi kopi, terutama di coffee shop; Adanya kenaikan permintaan kopi; Munculnya UKM pengolahan kopi baru sebagai kompetitor utama; Adanya Negara penghasil kopi lainnya; Munculnya sektor usaha baru yang membuat karyawan lebih memilih profesi lain yang menguntungkan. Sedangkan faktor internal Bauran Pemasaran kopi Dadong adalah Produksi dari biji kopi pilihan; Kondisi keuangan stabil dan cenderung meningkat; Reputasi yang baik dalam pelayanan baik pemesanan, produksi dan kecepatan dalam pengiriman barang; Memiliki kebun kopi mitra disekitar area produksi; Inovasi dalam proses pengolahan kopi terfermentasi; Belum menggunakan tenaga mesin kapasitas besar; Perencanaan jadwal produksi belum maksimal, dimana perencanan ditentukan dari besar kebutuhan; Tidak adanya pelatihan secara khusus kepada para karyawan baru sehingga proses produksi terganggu; Jaringan pemasaran secara nasional maupun ke luar negeri belum terjangkau; Kurangnya promosi.
\end{abstract}

Kata kunci: Lingkungan Internal, Lingkungan Ekternal, Bauran Pemasaran, Produk Kopi

\begin{abstract}
The internal environment illustrates that the company has strengths or weaknesses in the areas of production management, marketing and distribution operations, human resource organizations, finance and accounting. Meanwhile, the external environment is an analysis composed of groups of forces that arise and are beyond reach and are usually independent of the company's operational situation. The purpose of this study is to identify the internal and external factors of the marketing mix at the Coffee Dadong UKM in Belantih Village. Respondents in this study were Mr. Dharma and Mrs. Dewa Ayu as the owner of the Dadong coffee business. This study used a descriptive research design. This research design is used because it is able to describe the analysis of the internal and external environment in the marketing mix of Dadong Coffee products. From the research, it is known that the external factors of Dadong Coffee Marketing Mix are the existence of government support in terms of agricultural product exhibitions in the introduction of coffee products; The great interest of young people with urban lifestyles in consuming coffee, especially in coffee shops; There is an increase in coffee demands; The emergence of new coffee processing as the main competitors; The existence of other coffee producing countries; The
\end{abstract}


emergence of a new business sector that makes employees prefer other profitable professions. Meanwhile, the internal factors of the Dadong Coffee Marketing Mix are the production of selected coffee beans; Financial condition is stable and tends to increase; Good reputation in service both ordering, production and speed of delivery of goods; Have partner coffee gardens around the production area; Innovations in fermented coffee processing; Not yet using large capacity engine power; Production schedule planning has not been maximized, where planning is determined by the size of the need; There is no special training for new employees so that the production process is disrupted; The marketing network both nationally and abroad has not been reached; Lack of promotion.

Keywords: Internal Environment, External Environment, Marketing Mix, Coffee Products

\section{PENDAHULUAN}

Kopi merupakan salah satu komoditi ekspor non-migas yang memiliki prospek cukup cerah. Permintaan di dalam negeri juga semakin kuat dengan semakin berkembangnya sektor agroindustri (Sedana dan Astawa, 2016). Di Bali Kopi juga menjadi salah satu komoditas perkebunan yang diandalkan. Perkembangan kopi cukup pesat dimana menurut data Dinas Perkebunan Provinsi Bali tahun 2017, luas areal penanaman kopi mencapai 2.834 ha dengan produksi 3.473,43 ton (BPS Kabupaten Bangli, 2020). Hampir keseluruhan areal perkebunan kopi adalah perkebunan rakyat. Areal penanaman kopi di Provinsi Bali, terutama berada di Kabupaten Bangli dan Kabupaten Buleleng.

Peningkatan konsumsi kopi domestik Indonesia, selain didukung dengan pola sosial masyarakat dalam mengonsumsi kopi, juga ditunjang dengan harga yang terjangkau, kepraktisan dalam penyajian serta keragaman cita rasa yang sesuai dengan selera konsumen. Dengan meningkatnya taraf hidup dan pergeseran gaya hidup masyarakat perkotaan di Indonesia telah mendorong terjadinya pergeseran dalam pola konsumsi kopi khususnya pada kawula muda. Generasi muda pada umumnya lebih menyukai minum kopi instant, kopi three in one maupun minuman berbasis espresso yang disajikan di cafe.

Pemasaran merupakan sebuah faktor penting dalam suatu tahap permulaan dan berakhir dengan kebutuhan konsumen, atau bisa juga dikatakan suatu kegiatan komunikasi yang bertujuan untuk memberikan informasi mengenai produk atau jasa yang berkaitan dengan kepuasan pelanggan. Hal ini dapat dikatakan sebagai menawarkan produk yang disediakan oleh perusahaan dengan maksud agar tercipta kegiatan jual beli sebagai tujuan dari perusahaan dan pemenuhan kebutuhan oleh konsumen. Strategi pemasaran sangat penting untuk menghadapi pangsa pasar yang semakin sempurna. Dalam upaya meningkatkan dan mengembangkan daya saing, maka perlu adanya proyeksi yang jelas dan terencana mengenai prospek pemasaran kopi, sehingga dapat mengetahui dan memperhitungkan peluang pasar dan masalah yang akan dihadapi.Bauran pemasaran sebagai alat bagi pengusaha untuk mempengaruhi konsumen agar konsumennya kenal kemudian menyenangi produk dan melakukan transaksi pembelian, serta konsumen tersebut menjadi puas. Masing-masing variabel bauran pemasaran yaitu: Produk, Harga, Tempat, dan Promosi.

Analisis lingkungan internal memberikan gambaran bahwa perusahaan memiliki kekuatan (strengths) atau kelemahan (weakness) di bidang manajemen produksi, operasi pemasaran dan distribusi, organisasi sumber daya manusia, keuangan dan akuntansi. Adapun tujuan dilakukannya analisis internal adalah untuk mendapatkan faktor kekuatan yang akan digunakan dan faktor kelemahan yang akan diantisipasi keberadaanya. Analisis lingkungan eksternal adalah analisis yang tersusun dari sekumpulansekumpulan kekuatan-kekuatan yang timbul dan berada di luar jangkauan serta biasanya terlepas dari 
situasi operasional perusahaan. Menurut David (2004), faktor-faktor analisis lingkungan eksternal terdiri atas sosial, ekonomi, teknologi dan pemerintah. Berdasarkan hal-hal tersebut di atas maka perlu dilakukan penelitian mengenai faktor internal eksternal dalam bauran pemasaran produk UKM Kopi Dadong tersebut.Tujuan dari penelitian ini adalah Mengidentifikasi faktor internal dan eksternal bauran pemasaran pada UKM Kopi Dadong di Desa Belantih.

\section{METODE}

\section{Lokasi dan Waktu Penelitian}

Penentuan lokasi penelitian dilakukan dengan cara sengaja (purposive) yaitu di Usaha pengolahan kopi dadong Desa Belantih Kecamatan Kintamani Kabupaten Bangli, Provinsi Bali. Lokasi ini dipilih berdasarkan pertimbangan, sebagai berikut: Usaha pengolahan kopi dadong Desa Belantih melakukan tiga proses pengolahan kopi arabika (Full washed, Honey dan Natural) dan 2) Pada usaha pengolahan kopi dadong Desa belantih merupakan UKM yang sedang berkembang dalam memasarkan produknya. Penelitian ini dilakukan pada bulan Desember 2019.

\section{Penentuan Responden}

Responden dalam penelitian ini adalah bapak Dharma dan ibu Dewa Ayu sebagai pemilik usaha kopi dadong di Desa Belantih. Pemilihan responden dengan metode purposive berdasarkan pertimbangan, bahwa pemilik usaha kopi dadong tersebut mengetahui dan mencatat kegiatan pemasaran dalam usaha yang dikelolanya.

\section{Metode Analisis Data}

Penelitian ini menggunakan rancangan penelitian deskriptif. Rancangan penelitian ini di gunakan karena mampu menggambarkan analisis lingkungan internal dan eksternal dalam bauran pemasaran produk Kopi Dadong. Hal ini sejalan dengan pendapat Bogdan dan Taylor (dalam Moleong, 2018) yang mengemukakan bahwa prosedur penelitian menghasilkan data deskriptif berupa kata atau lisan dari orang-orang dan perilaku yang dapat di amati. Objek dalam penelitian ini adalah lingkungan internal dan eksternal dalam bauran pemasaran perusahaan yang akan dikaji dalam variabel SWOT, yakni kekuatan, kelemahan, peluang dan ancaman.

\section{HASIL DAN PEMBAHASAN}

\section{Sejarah Perusahaan}

Pengolahan kopi greenbean arabika dengan nama "pengolahan kopi dadong" mulai berdiri dari tahun 2005 pada bulan Agustus yang diawali dengan mengilah kopi robusta serbuk dengan pasar masyarakat kecil dan dengan produksi dengan pasca kecil. Setelah tahun 2012 pabrik atau perusahaan ini berkembang menjadi salah satu penghasil kopi greenbean berkualitas, proses pengolahaannya didapatkan secara otodidak dan riset dari beberapa pengolah biji kopi greenbean di Desa Belantih.

Perusahaan pengolahan ini dimiliki oleh pasangan suami istri yang bernama Bapak Dharma dengan Ibu Dewa ayu. Dengan memiliki luas bangunan $500 \mathrm{~m}^{2}$ untuk lahan pengolahan kopi mentah hingga menjadi greenbean. Mereka mempunyai karyawan hingga 15 orang, namun beberapa karyawan tidak setiap hari bekerja, hanya 5 orang saja yang hampir sering ada dan tugasnya hanya sortirasi biji greenbean 
yang sudah jadi dan sipa dipasarkan untuk di rosting oleh roster. Tetapi misalkan jika musim panen 15 orang tersebut bekerja dengan sistem borongan.Perusahaan ini mulai tumbuh dari sebuah industri rumah tangga sederhana tanpa menggunakan mereka.

Sehubungan dengan kualitas kopi yang selalu dijaga, permintaan akan kopi semakin berkembang. Pada tahun 2012, karena banyaknya permintaan dari konsumen, lalu perusahan tersebut memproduksi produk baru dengan merek "kopi dadong" pada tahun 2012 dengan harga yang sangat terjangkau tetapi tidak mengurangi kualitas dari kopi. Perusahaan ini selalu menggunakan bahan-bahan yang terbaik sehingga menjadikan Kopi arabika yang berkualitas.

\section{Faktor Internal Bauran Pemasaran Kopi Dadong}

Analisis strategi internal perusahaan merupakan analisis untuk merumuskan dan mengevaluasi kekuatan dan kelemahan di dalam perusahaan itu sendiri, juga memberikan suatu dasar bagi identifikasi dan evaluasi hubungan fungsional perusahaan dengan pesaingnya(Ramdani \& Supriyat, 2014).

\section{Kekuatan}

Kekuatan dalam bauran pemasaran produk UKM Kopi dadong terdiri dari:

(1) Produksi dari biji kopi pilihan.

Atribut produk adalah suatu komponen yang merupakan sifat-sifat produk yang menjamin agar produk tersebut dapat memenuhi kebutuhan dan keinginan diharapkan oleh pembeli (Gitosudarmo, 2000). Produk dengan kualitas yang baik akan diminati oleh konsumen. Produk Kopi Dadong diproduksi dari biji kopi pilihan dengan pengolahan terfermentasi yang akan memberikan kualitas terbaik pada produk kopi olahannya. Berdasarkan hasil penelitian, produk yang dihasilkan adalah berupa kopi bubuk. Kopi bubuk tersebut diberi merek Kopi Dadong. Bentuk produk yang dihasilkan oleh Kopi Dadong berupa bubuk hitam dan warna kopi bubuk tersebut sangat pekat.Perusahaan dalam bertahan dan berkembang harus mampu mempertahankan serta meningkatkan kualitas produknya sehingga dapat bersaing di pasaran (Purwono et al., 2008)

(2) Kondisi keuangan stabil dan cenderung meningkat.

Laporan keuangan didokumentasikan dengan baik di UKM Kopi Dadong, sehingga dapat memberikan informasi yang tepat untuk melakukan kebijakan pemasaran produknya.

(3) Reputasi yang baik dalam pelayanan baik pemesanan, produksi dan kecepatan dalam pengiriman barang.

Distribusi memiliki peranan yang sangat pentingdalam membantu perusahaan guna memastikan produknya. Hal ini dikarenakan tujuan dari distribusi adalah menyediakan barang dan jasa yang dibutuhkan dan diinginkan oleh konsumen pada waktu dan tempat yang tepat. Produk yang dikirim dengan tepat waktu akan memberikan pelayanan yang baik kepada konsumen, sehingga konsumen merasa puas terhadap pelayanan yang telah diberikan oleh UKM Kopi Dadong.

(4) Memiliki kebun kopi mitra disekitar area produksi.

Kebun kopi yang berada disekitar area produksi, memberikan keuntungan bagi UKM Kopi Dadong. Hal tersebut dikarenakan akan mengurangi biaya transportasi bahan baku, yang berdampak pada penghematan biaya. Selain itu, pengawasan dalam pemetikan biji kopi pilihan dapat diawasi dengan mudah. 
(5) Inovasi dalam proses pengolahan kopi terfermentasi.

Biji kopi yang diolah merupakan biji kopi pilihan yang difermentasi yang akan memberikan kualitas cita rasa yang baik. Dengan terus melakukan inovasi maka akan meningkatkan kualitas produk dapat membuat pelanggan akan tetap loyal terhadap produk yang ditawarkan(Suparyana et al., 2020)

\section{Kelemahan}

Kelemahan dalam bauran pemasaran produk UKM Kopi dadong adalah:

(1) Belum menggunakan tenagamesin kapasitas besar.

Kemajuan teknologi dalam pengolahan kopi harus selalu diperbaharui agar memberikan efisiensi dalam produksi. Akan tetapi pembaharuan teknologi juga harus mempertimbangkan jumlah permintaan kopi yang dipasarkan.

(2) Perencanaan jadwal produksibelum maksimal, dimana perencanan ditentukan daribesar kebutuhan. Tanggungjawab dan wewenang setiap bidang pembagiannya harus dikoordinasikan pada awal kegiatan agar memperlancar proses produksi. Peramalan penjualan seharusnya dianalisa dengan menggunakan data-data penjualan pada periode sebelumnya agar dapat ditentukan jumlah produksi yang sesuai dan tidak mengalami kekurangan atau kelebihan produksi. Tidak adanya perputaran kerja jam kerja juga dapat mempengaruhi efisiensi dari SDM yang ada, yang dapat berdampak pada kualitas dan kuantitas produksi.

(3) Tidak adanya pelatihan secarakhusus kepada para karyawanbaru sehingga proses produksiterganggu.

SDM yang terampil akan memberikan efisiensi dalam produksi. Kurangnya pelatihan akan memberikan dampak bagi kualitas dan kuantitas dari produk Kopi Dadong. Karena UKM masih dalam keadaan berkembang, sehingga tidak adanya pelatihan menjadi kelemahan dalam bauran pemasaran di UKM Kopi Dadong.

(4) Jaringan pemasaran secara nasional maupun ke luar negeri belum terjangkau.

Jaringan pemasaran terkait dengan distribusi produk. Distribusi adalah proses sampainya barang dari produsen ke konsumen. Saat ini UKM Kopi Dadong masih merasa kesulitan untuk dapat menyalurkan produknya hingga sampai ke tangan konsumen, terutama konsumen nasional dan luar negeri. Dengan jaringan yang luas diharapkan dapat meningkatkan penjualan produk Kopi Dadong. Sehingga belum tersebarnya produk secara nasional dan luar negeri menjadi kelemahan dari UKM Kopi Dadong.

(5) Kurangnya promosi.

Promosi yang dilakukan masih belum maksimal. Kegiatan promosi dilakukan untuk memperkenalkan dan mempengaruhi konsumen serta menarik konsumen secara langsung terhadap produk yang dihasilkan. Promosi adalah cara yang efektif dalam merebut konsumen dipasaran, serta memperkenalkan barang-barang baru yang diproduksi. Promosi yang dilakukan oleh UKM Kopi Dadong masih berupa promosi dari mulut ke mulut serta melalui media sosial sehingga perlu untuk dilakukan peningkatan dalam promosi yang dilakukan. Promosi melalui media sosial juga dapat digunakan untuk mempromosikan produk sehingga dapat memberi peningkatan penjualan (Indika \& 
Jovita, 2017; Indrawati et al., 2017; Reinhart Abedneju Sondakh et al., 2019; Setiawan et al., 2019; Untari \& Fajariana, 2018)

\section{Faktor Eksternal Bauran Pemasaran Kopi Dadong}

Analisis lingkungan eksternal adalah analisis mengenai faktor-faktor eksternal ataumerupakan situasi dan kondisi yang berada di luar organisasi secara langsung atau tidaklangsung dapat mempengaruhi kinerja organisasi(Ramdani \& Supriyat, 2014). Tujuan dari analisis lingkungan eksternaladalah untuk mengembangkan suatu daftar peluang (opportunity) yang dapat dimanfaatkanoleh organisasi dan daftar ancaman (threats) yang harus dihindari oleh organisasi. Keduadaftar ini harus memuat faktor-faktor kunci yang mempengaruhi lingkungan eksternal dimanaorganisasi bergerak. Strategi yang dikembangkan oleh organisasi harus mampumemanfaatkan peluang-peluang yang ada dan menghindari ancaman-ancaman yangmembahayakan organisasi.

\section{Peluang}

Peluang dalam bauran pemasaran produk UKM Kopi dadong adalah:

(1) Adanya dukungan pemerintah dalam hal pameran produk pertanian dalam pengenalan produk kopi. Pemerintah Daerah yang turut memberikan dukungan kepada kegiatan UKM ini adalah Dinas Pertanian Provinsi. Dinas ini memberikan dukungan dalam bentuk pemberian stan dalam pameran untuk memperkenalkan produk kepada konsumen

(2) Besarnya minat pemuda dengan lifestyle diperkotaandalam mengkonsumsi kopi, terutama di coffee shop.

Saat ini konsumen,terutama kawula muda sudah pada tahap hobi dalam konsumsi kopi. Tren lifestyle ini telahmenjadi semakin memasyarakat. Konsumen cenderung lebih memilih produk kopi dengan cita rasa khas untuk dikonsumsi. Salah satu indikator produk yang khas adalah produk dengan pengolahan melalui proses fermentasi dan biji kopi pilihan. Produk olahan UKM Kopi Dadong ini diproduksi dengan biji kopi pilihan. Dengan demikian konsumen akan merasa menikmati untuk mengkonsumsi produkini.

(3) Adanya kenaikan permintaan kopi.

Dengan memiliki kualitas produk yang baik maka konsumen akan menjadi loyal dan percaya akan kualitas dan cita rasa produk yang dihasilkan UKM Kopi Dadong. Ini dibuktikan dengan meningkatnya permintaan konsumen terutama pelanggan tetap setiap tahunnya. Permintaan dari coffee shop dan pemesanan secara langsungpun semakin meningkat, ini menjadi peluang bagi UKM Kopi Dadong dalam mengembangkan usahanya

\section{Ancaman}

Ancaman dalam bauran pemasaran produk UKM Kopi dadong adalah:

(1) Munculnya UKM pengolahan kopi barusebagai kompetitor utama.

Terdapat pesaing dari UKM lain di wilayah Bangli yang melakukan pengolahan kopi. Produk yang dihasilkan tidak jauh berbeda, begitu pun dengan skala usahanya yaitu skala UKM. Kelebihannya dalam segi kualitas, kualitas produk UKM Kopi Dadong lebih unggul. Keberadaan UKM ini menjadi ancaman bagi UKM Kopi Dadong dalam memasarkan produknya karena akan menimbulkan persaingan dalam industri pengolahan kopi 
(2) Adanya Negara penghasil kopi lainnya.

Petani kopi dari Negara lain akan terus meningkatkan kualitas komoditas kopi, karena tingginya permintaan konsumen. Hal ini akan menjadi ancaman jika tidak diperhatikan dengan baik.

(3) Munculnya sektor usaha baruyang membuat karyawan lebihmemilih profesi lain yangmenguntungkan.

Kekurangan tenaga kerja akan menjadi perhatian jika, manajemen tidak mampu memberikan imbal jasa yang baik dan suasana kerja yang nyaman. Olehkarenanya ancaman ini harus ditanggapi dengan baik, karena banyaknya pekerjaan lain saat musim panen tiba di Desa Belantih.

\section{PENUTUP}

\section{Simpulan}

Faktor-faktor yang berperan dalam bauran pemasaran produk UKM Kopi Dadong terdiri dari faktor internal dan faktor eksternal. Kedua faktor ini perlu menjadi fokus utama bagi perusahaan agar dapat terus bertahan dalam persaingan. Faktor Eksternal Bauran Pemasaran Kopi Dadong adalah Adanya dukungan pemerintah dalam hal pameran produk pertanian dalam pengenalan produk kopi; Besarnya minat pemuda dengan lifestyle diperkotaan dalam mengkonsumsi kopi, terutama di coffee shop; Adanya kenaikan permintaan kopi; Munculnya UKM pengolahan kopi baru sebagai kompetitor utama; Adanya Negara penghasil kopi lainnya; Munculnya sektor usaha baru yang membuat karyawan lebih memilih profesi lain yang menguntungkan.

Faktor Internal Bauran Pemasaran Kopi Dadong adalah Produksi dari biji kopi pilihan; Kondisi keuangan stabil dan cenderung meningkat; Reputasi yang baik dalam pelayanan baik pemesanan, produksi dan kecepatan dalam pengiriman barang; Memiliki kebun kopi mitra disekitar area produksi; Inovasi dalam proses pengolahan kopi terfermentasi; Belum menggunakan tenaga mesin kapasitas besar; Perencanaan jadwal produksi belum maksimal, dimana perencanan ditentukan dari besar kebutuhan; Tidak adanya pelatihan secara khusus kepada para karyawan baru sehingga proses produksi terganggu; Jaringan pemasaran secara nasional maupun ke luar negeri belum terjangkau; Kurangnya promosi.

\section{Saran}

Produk UKM Kopi Dadong disarankan untuk mengantisipasi ancaman-ancaman dan memanfaatkan peluang serta memaksimalkan kekuatan serta meminimalkan kelemahan yang ada. Produk UKM Kopi Dadong dapat memanfaatkan Faktor Internal dan eksternal tersebut dalam bauran pemasaran produknya.

\section{DAFTAR PUSTAKA}

BPS Kabupaten Bangli. (2020). Kabupaten Bangli Dalam Angka 2020. BPS Kabupaten Bangli. https://banglikab.bps.go.id/publication/2020/04/27/7bf1ef69f11fb2653d0119a9/kabupaten-banglidalam-angka-2020.html

David, F. R. (2004). Manajemen Strategis Konsep-konsep Edisi Kesembilan. PT. Indeks. Jakarta.

Gitosudarmo, I. (2000). Manajemen Pemasaran (Edisi 1). BPFE. http://opacdkp.jambikota.go.id/inlislite3/opac/detail-opac?id=20988

Indika, D. R., \& Jovita, C. (2017). Media Sosial Instagram Sebagai Sarana Promosi Untuk Meningkatkan Minat Beli Konsumen. Jurnal Bisnis Terapan, 1(01), 32. https://doi.org/10.24123/jbt.v1i01.296 
Indrawati, K. A. P., Sudiarta, I. N., \& Suardana, I. W. (2017). Efektivitas Iklan Melalui Media Sosial Facebook Dan Instagram Sebagai Salah Satu Strategi Pemasaran Di Krisna Oleh-Oleh Khas Bali. Jurnal Analisis Pariwisata, 17(2), 78-83. https://ojs.unud.ac.id/index.php/jap/article/view/36484

Moleong, L. J. (2018). Metodologi penelitian kualitatif (Edisi Revisi). PT Remaja Rosdakarya. https://opac.perpusnas.go.id/DetailOpac.aspx?id=1133305

Purwono, J., Sugyaningsih, S., \& Novianti, R. (2008). Strategi Pengembangan Bisnis Bibit Tanaman Hutan (Kasus PT Sarbi Moerhani Lestari, Bogor). Jurnal Berkala Ilmu Ekonomi, 2(1), 34-54. https://doi.org/10.21107/NBS.V2I1.560

Ramdani, S. H., \& Supriyat, F. (2014). Analisis Faktor Eksternal Dan Internal Untuk Menentukan Strategi Pemasaran Pada CV Certowin Multi Trading Indonesia. JIMFE (Jurnal Ilmiah Manajemen Fakultas Ekonomi), 6(1), 48-55. https://doi.org/10.34203/jimfe.v6i1.492

Reinhart Abedneju Sondakh, Endang Erawan, \& Sarwo Edy Wibowo. (2019). Pemanfaatan Media Sosial Instagram Pada Akun @Geprekexpress Dalam Mempromosikan Restoran Geprek Express. Llmu Komunikasi, 7(1), 279-292. https://ejournal.ilkom.fisip-unmul.ac.id/site/?p=3812

Sedana, G. and N.D. Astawa. (2016). Panca Datu Partnership in Support of Inclusive Business for Coffee Development:The Case of Ngada District, Province of Nusa Tenggara Timur, Indonesia. Asian Journal of Agriculture and Development, Vol. 13, No.2: 75-98.

Setiawan, I. M. D., Sukanteri, N. P., Suryana, I. M., \& Suparyana, P. K. (2019). Pengaruh Promosi Berbasis Sosial Media Terhadap Penjualan Produksi Kelompok Wanita Tani (KWT) Ayu Tangkas Di Desa Megati. Jurnal Ilmu Sosial Dan Humaniora, 8(2), 227-234. https://doi.org/10.23887/JISHUNDIKSHA.V8I2.22375

Suparyana, P. K., Sukanteri, N. P., \& Septiadi, D. (2020). Stategi Pengembangan Usaha Produksi Kue Pada Kelompok Wanita Tani Ayu Tangkas Di Kecamatan Selemadeg Timur, Bali. AGRISAINTIFIKA: Jurnal Ilmu-Ilmu Pertanian, 4(1), 46-59. https://doi.org/10.32585/ags.v4i1.844

Untari, D., \& Fajariana, D. I. (2018). Strategi Pemasaran Melalui Media Sosial Instagram (Studi Deskriptif Pada Akun @Subur_Batik). Widya Cipta - Jurnal Sekretari Dan Manajemen, 2(2), 271-278. https://doi.org/10.31294/WIDYACIPTA.V2I2.4387

Wijaya, B. R., Martiningsih, N. G. A. G. E., \& Suparyana, P. K. (2019). Efesiensi Usaha Pengolahan Kopi Dengan Beberapa Metode (Studi Kasus Pada Usaha Kopi Dadong). Agrimeta: Jurnal Pertanian Berbasis Keseimbangan Ekosistem, 9(17), 41-46. 